\title{
Sobre a educação cultural e ético-política dos professores
}

\section{On cultural and ethical-political education of teachers}

\author{
Licínio C. Lima ${ }^{1}$
}

\begin{abstract}
RESUMO
A formação de professores como educadores profissionais tem sido dominada pela razão instrumental. Políticas educativas baseadas no gerencialismo, na performance competitiva da escola, em padrões de avaliação, têm sublinhado a necessidade de um novo tipo de professor: um professor altamente racional, dotado de um perfil fortemente técnico. Instituições de formação também têm mudado os seus projetos educativos para a formação de professores, agora muito centrados nas novas tecnologias e em instrumentos práticos para a ação didática, para avaliações de todo o tipo, para a microgestão da sala de aula e para a medição através de testes, o uso de padrões e a produção de evidência empírica sobre o seu trabalho. Estas tendências instrumentais e os riscos envolvidos no processo de didatização da educação dos professores são criticados com base na importância de uma educação cultural e ético-política de professores. Os trabalhos de Paulo Freire foram escolhidos como a principal fonte para refletir sobre algumas das exigências básicas para alguém se tornar um professor, de acordo com uma agenda democrática e crítica. De acordo com a prespectiva freiriana, as possíveis contribuições resultantes de uma educação emancipatória e transformadora de educadores profissionais exigirão a capacidade de combinar formação técnica, científica e profissional com educação política, sonho e utopia.

Palavras-chave: formação de professores; educação cultural; educação ético-política; Paulo Freire.
\end{abstract}

DOI: $10.1590 / 0104-4060.46864$

1 Instituto de Educação da Universidade do Minho e Centro de Investigação em Educação. Braga, Portugal. Campus de Gualtar, 4710-057.E-mail: 1lima@ie.uminho.pt 


\begin{abstract}
The training of teachers as professional educators has been dominated by instrumental reason. Education policies based on managerialism, competitive school performance, evaluation standards and vocationalism have been stressing the need for a new type of teacher: a highly rational teacher with a strong technical profile. Training institutions have also changed their education projects for the preparation of teachers, now much based on new technologies and practical instruments for didactic action, for evaluations of all kinds, for the micro-management of classrooms and the measurement by tests, using standards and producing empirical evidence of their work. These instrumental tendencies and the risks involved in the process of didactization of teachers' education are criticized on the basis of the importance of a cultural and ethical-political education of teachers. The works by Paulo Freire have been chosen as the main source to reflect upon some of the basic demands for becoming a teacher according to a democratic and critical agenda. According to the Freirean perspective, the possible contributions resulting from an emancipatory and transformative education of professional educators will demand the capacity of combining technical, scientific and professional training with political education, dream and utopia.
\end{abstract}

Keywords: teachers training; cultural education; ethical-political education; Paulo Freire.

\title{
Introdução
}

Os professores, que são educadores profissionais, não nascem professores e muito menos nascem educados para o exercício da profissão, por mais força que continuem a manter as concepções idealistas sobre a "vocação", sobre o fado de se ter nascido para se ser professor(a), geralmente acompanhadas pela ideologia dos "dons" ou dos talentos. Sabe-se, pelo contrário, como em certas circunstâncias históricas e como no contexto de certas classes sociais, a par das diferenças de género e outras, o magistério se apresentou como um "destino" social racionalmente calculado pelas famílias, seja como fator de mobilidade social ascendente, seja, noutros casos e inversamente, como último recurso, na tentativa de conter uma maior perda de status perante uma origem social representada como superior.

No processo socio-histórico de se tornar uma profissão e de se ver reconhecida, e controlada, pelo Estado (NÓVOA, 1987), o trabalho dos professores foi institucionalmente inscrito numa organização escolar capaz de produzir ensino 
em grande escala, dotada de regras e formas racionais de ação organizada e de gestão do trabalho docente, em torno de um currículo especializado e fragmentado, de métodos de ensino e de avaliação, de uma burocracia fortemente marcada pelo contexto industrial. (TARDIF; LESSARD, 2007, p. 24-28).

Já em 1657, na sua Didática Magna, João Amós Coménio apresentava um tratado da arte universal de ensinar tudo a todos e em todos os lugares, para esse efeito recomendando uma reforma das escolas que tivesse por fundamento "a ordem exata em tudo". (COMÉNIO, 1976, p. 181). A racionalização do processo de ensino, possibilitada pelo maior acesso ao conhecimento através do livro impresso, era metaforicamente inspirada pela exatidão e organização de um relógio, "[...] construído segundo as regras da arte e elegantemente ornado de cinzeladuras variadas". (COMÉNIO, 1976, p. 186). Isso exigia formar professores na "arte de ensinar", baseada numa "habilidosa repartição do tempo, das matérias e do método", o que, uma vez alcançado, possibilitaria ensinar tudo à juventude escolar, sem dificuldade para os professores, que até então ignoravam como ensinar metodicamente, e, para os estudantes, "[...] sem tédio, sem gritos e sem pancadas, como que divertindo-se e jogando". (COMÉNIO, 1976, p. 73).

As bases científicas e técnico-racionais do trabalho docente, seja no plano dos conteúdos, ou matérias a ensinar, seja também no que concerne ao contexto organizacional escolar e aos métodos, ficavam claramente apontadas e associadas sob o signo da referida imagem mecanicista do relógio. Mas, curiosamente, ainda sem antagonismos desnecessários entre forma e conteúdo, ao contrário do que sucederá mais tarde, e ainda hoje, com certas perspectivas que entendem ser possível cindir as matérias e os processos de ensino-aprendizagem; separar os conteúdos a ensinar dos fins e objetivos da educação escolar, dos seus contextos sociais, dos sujeitos em presença e dos métodos de ensino praticados. Em suma, como se fosse possível, e mais ainda desejável, isolar o científico do pedagógico, o administrativo do didático, o cultural das teorias educacionais, o político do educativo, incorrendo naquilo a que, em termos mais gerais, John Dewey (2007, p. 280-281) chamou o "dualismo" entre a matéria e o método.

Há quase três décadas, no seu livro intitulado La formation des enseignants, também Gaston Mialaret (1977) procurou abordar, de forma articulada, mas ainda assim passível de crítica quanto aos termos escolhidos, aquilo que designou por "formação académica" e por "formação pedagógica", recusando a sua oposição e a sua mera justaposição. Para Mialaret era claro que não existia qualquer possibilidade de vir a ter bons professores a partir de ignorantes, sem a necessária "formação académica". Mas, por outro lado, tal formação, desligada da "formação pedagógica", não constituía condição suficiente para garantir bons educadores. A dualidade - não o dualismo - daí resultante, reconduzia Mialaret, em última instância, à unidade que, em torno do conceito de educação, 
ele estabeleceu entre o político e o científico. Como esclareceu naquela obra, a educação pertence ao político, sendo um problema político, tanto mais quanto é impossível concebe-la e praticá-la à margem de uma concepção de ser humano, de sociedade e de natureza, de valores e de cultura.

Há muito tempo que se havia chamado a atenção para a condição política da educação, ou para o fato de a política ser imanente à educação, de resto a propósito da educação dos educadores. Na terceira das onze teses que Karl Marx esboçou sobre o filósofo materialista Ludwig Andreas von Feuerbach, em texto de 1845, coloca-se o dilema de saber como seria possível educar para a transformação quando os seres humanos, e desde logo os próprios educadores, são "produtos das circunstâncias e da educação", o que dificultaria a mudança, já que esta só com uma educação diferente poderia ser viabilizada. Marx (1971, p. 22), porém, esclarece que tal doutrina materialista “[...] esquece que são precisamente os homens que transformam as circunstâncias e que o próprio educador tem necessidade de ser educado", (MARX, 1971, p. 22). Nesse sentido, ficava uma vez mais sinalizada a ideia da educação permanente dos próprios educadores, ideia que, em termos mais globais, havia sido apresentada, entre outros, pelo filósofo francês Claude-Adrien Helvétius, de resto comentado por Marx, a propósito do materialismo francês, em $A$ sagrada família (MARX; ENGELS, 2011). Helvétius, na sua obra póstuma intitulada De l'Homme, de ses facultés intellectuelles et de son education, publicada em 1773, afirmou: "O curso da minha vida não é mais do que um longo processo de educação". (HELVÉTIUS, 1773, p. 12). Embora prefigurando o princípio da educação permanente, ou ao longo da vida, e defendendo a importância da educação pública e moral dos cidadãos, o autor adotou uma concepção hiperbólica do poder da educação a partir da máxima de que a educação faz tudo, ou pode tudo, o que lhe valeu diversas críticas pelo seu manifesto pedagogismo (cf. LIMA, 2010).

Qualquer abordagem demiúrgica e todo-poderosa de educação acaba por ser confrontada com as dificuldades da mudança da sociedade, da cultura e da economia e, ainda, com os limites das suas capacidades para transformar a própria educação, mesmo quando se pede aos professores que lutem contra as instituições educativas tradicionais. Antonio Gramsci observou-o com grande lucidez ao admitir que foi correto lutar contra a velha escola, embora a sua reforma não se tivesse revelado tão simples quanto tinha parecido, tendo conluído: "O problema não era o do modelo curricular mas o de homens, e não apenas o dos homens que são realmente professores, mas o de todo o complexo social que eles expressam". (GRAMSCI, 1971, p. 37).

Não obstante as diferenças entre Gramsci e Paulo Freire no que se refere à concepção de educador, estudadas entre outros por Diana Coben (2001, p. 158160), sobressaindo no primeiro o Estado e o seu papel hegemónico e educativo 
("Estado-educador") e também o partido político e o indivíduo, tendo em vista alcançar uma cidadania governante e com capacidade de liderança própria, e no segundo uma pedagogia do oprimido, baseada numa relação pedagógica de tipo dialógico, há contudo semelhanças entre as relações estabelecidas por ambos entre práticas educativas e possibilidades de transformação democrática. Como observou, com pertinência, Peter Mayo (1999, p. 155), em ambos os autores as práticas educativas são concebidas não como processos neutros, mas antes como atos políticos. Além disso, também aqueles dois autores partilharam a ideia de que estudar representa um trabalho, um trabalho difícil e muito exigente, exatamente ao invés do que afirmam hoje as críticas conservadoras relativamente à chamada pedagogia moderna e às suas pretensas derivas naturalistas, quase sempre ignorando as teses da pedagogia crítica e pedagogos políticos como Freire. Exatamente porque quem aprende não é um recipiente vazio e passivo, mas antes um sujeito ativo e criativo, Gramsci (1971, p. 42) chamará a atenção para a importância da autodisciplina e do necessário esforço envolvido no estudo, incluindo "músculos e nervos, assim como intelecto".

Já em Freire, aquela questão merecerá profunda e frequente referência nos seus trabalhos, implicando necessariamente os próprios professores e as exigências que se colocam ao ato de ensinar. Em finais da década de 1960, então exilado no Chile, Freire escreverá um pequeno texto intitulado "Considerações em torno do ato de estudar", que coligiu em 1975 no seu livro Ação cultural para a liberdade e outros escritos. (FREIRE, 2001). Aqui observa a incompatibilidade entre as dificuldades e as exigências do ato de estudar, por uma lado, e a "disciplina" para a ingenuidade, para a não criticidade, promovida pela "educação bancária", que criticaria em 1970, na sua Pedagogia do oprimido (FREIRE, 1975), opondo-lhe uma concepção "problematizadora e libertadora" de educação. Escreveu o autor a propósito, dirigindo-se aos participantes num seminário: "Estudar é, realmente, um trabalho difícil. Exige de quem o faz uma postura crítica, sistemática. Exige uma disciplina intelectual que não se ganha a não ser praticando-a". (FREIRE, 2001, p. 10). Tal exigência é, para Freire, tipicamente uma exigência crítica, de sujeitos e não de "consumidores" de textos, e por isso estudar é "[...] uma forma de reinventar, de recriar, de reescrever tarefa de sujeito e não de objeto" (FREIRE, 2001, p. 10-11).

\section{A condição cultural e ético-política da formação de professores}

$\mathrm{O}$ ato de estudar, tal como o ato de ensinar e de aprender, é concebido por Paulo Freire como um ato cultural e ético-político, muito mais do que como, 
simplesmente, um ato estritamente escolar, didático, ou um instrumento privilegiado de preparação para os exames. Implica, de resto, e de forma igualmente importante, os professores e os seus alunos, em diálogo, estudando a realidade e, cada um a seu modo e de acordo com as suas experiências anteriores, procurando realizar a sua vocação de "saber mais" e de "ser mais", uma vez que uns e outros são considerados seres históricos, finitos, inconclusos, em permanente processo de indagação. Aqui reside, para Freire, a justificação maior da necessidade de uma educação e formação permanentes, dado que "O ser humano jamais para de educar-se". (FREIRE, 1997a, p. 21). A educação como processo de conhecimento e de humanização dos seres humanos é um ato cultural e ético-político, tal como a formação de educadores profissionais é impossível de conceber à margem de uma ação cultural e de uma alfabetização política de adultos.

Ensinar implica estudar e esse é, também, um testemunho fundamental para os alunos e para a “[...] necessidade da disciplina intelectual a ser construída pelos educandos em si mesmos com a colaboração da educadora". (FREIRE, 1997b, p. 115). A formação de professores revela-se de uma extraordinária exigência científica e político-cultural, acarretando enorme responsabilidade ética. Desde logo porque a prática educativa é, como diz Freire, "algo de muito sério":

Lidamos com gente, com crianças, adolescentes ou adultos. Participamos de sua formação. Ajudamo-los ou os prejudicamos nesta busca. Estamos intrinsecamente a eles ligados no seu processo de conhecimento. Podemos concorrer com a nossa incompetência, má preparação, irresponsabilidade, para o seu fracasso. Mas podemos, também, com a nossa responsabilidade, preparo científico e gosto do ensino, com a nossa seriedade e testemunho de luta contra as injustiças, contribuir para que os educandos vão se tornando presenças marcantes no mundo. (FREIRE, 1997b, p. 47).

Ensinar, aprender, conhecer, estudar são, para Freire, termos indissociáveis que remetem para a disciplina e a exigência, incompatíveis com o "puro entretenimento", mas não necessariamente atos enfadonhos e incompatíveis com a alegria e o prazer da descoberta. Nesse processo, o papel dos professores é crucial, desde logo pelo seu testemunho de disciplina no trabalho intelectual e pela autoridade que os outros the reconhecem com base na sua competência, na sua capacidade de decidir, na sua coerência ético-política, no seu querer bem aos educandos. Como escreve em Pedagogia da esperança: 
Um professor que não leva a sério sua prática docente, que, por isso mesmo, não estuda e ensina mal o que mal sabe, que não luta para que disponha de condições materiais indispensáveis à sua prática docente, se proíbe de concorrer para a formação da imprescindível disciplina intelectual dos estudantes. Se anula, pois, como professor. (FREIRE, 1997c, p. 83).

Ao conceber a prática docente como prática educativa, Freire torna-se especialmente exigente para com os professores e a sua formação, recusando antinomias simplistas. A seriedade que exige aos professores não dispensa a seriedade das autoridades e o seu compromisso político para com a democratização da educação; a autoridade docente que propõe não é confundível com a imposição da autoridade nem com a inibição da liberdade, de que resulta o autoritarismo; a alegria de que fala é elemento nuclear numa escola viva, feita de relações humanas que visam à humanização dos participantes, ao seu diálogo, à sua cooperação no trabalho escolar, em nada podendo ser confundida com licenciosidade ou anarquia; a democracia e a justiça são consideradas cruciais, não apenas como conteúdos que são objetos do ensino, mas especialmente como práticas que atravessam a escola e a sala de aula, em diálogo com a comunidade, visando a educação política e cidadã dos educandos. Quando no seu livro $A$ sombra desta mangueira se refere ao "educador democrata" caracteriza-o assim:

A satisfação com que se põe em face dos alunos, a segurança com que lhes fala, a abertura com que os ouve, a justiça com que lida com os seus problemas fazem do educador democrata um modelo. Sua autoridade se afirma sem desrespeitar as liberdades. Se afirma precisamente por isso. Um educador democrata não pode atrofiar sua autoridade, com o que hipertrofia a liberdade dos educandos. Não pode contradizer-se em favor de sua autoridade, nem em favor da liberdade dos educandos. Nem autoritarismo, nem licenciosidade. (FREIRE, 2000, p. 72).

Também o contexto específico da formação de professores ficará impedido de contradizer-se, não apenas pela reconhecida importância do isomorfismo entre formação inicial e prática educativa em contextos escolares concretos, mas especialmente porque é em contexto de formação que os valores da democracia e da liberdade, da autonomia e da prática da decisão, da responsabilidade e da ética hão de começar por ser afirmados e vivenciados. Por isso Freire insistiu em que, não podendo ser neutra a educação, esse fato coloca os educadores perante a imperatividade de optar, isto é, "de dizer, de decidir, de romper, de escolher" 
(FREIRE, 1997a, p. 39), bem como de assumir coerente e responsavelmente as opções feitas. Como observei noutro lugar (LIMA, 2011), é por essa razão que Freire procede a uma crítica da educação indecisa. Pelo contrário, uma pedagogia da decisão exige, segundo ele, a prática democrática da decisão, não apenas enquanto processo político de democratização dos poderes educativos e de exercício da autonomia democrática, mas também enquanto processo pedagógico: aprender democracia pela prática da participação na decisão. Como afirmou a este propósito, "A capacidade de decisão da educadora ou do educador é absolutamente necessária a seu trabalho formador. É testemunhando sua habilitação para decidir que a educadora ensina a difícil virtude da decisão". (FREIRE, 1997b, p. 60). Inversamente, a não participação no processo de tomada de decisões em educação, a passividade e acomodação, o medo da liberdade, são elementos típicos da alienação dos professores e dos alunos, contra a concepção de educação como prática da liberdade.

A formação docente é também, e sempre, um processo de socialização dos futuros educadores e professores, não apenas relativamente a disposições científicas, a comportamentos académicos e a hábitos culturais, mas ainda em torno de visões do mundo, de concepções de educação e de sociedade, de democracia e de justiça. A educação, como coisa política, compreende opções antropológicas e éticas, explícitas e, noutros casos, apenas implícitas, à margem das quais seria simplesmente impossível o ato educativo, o processo de ensino-aprendizagem, a relação pedagógica e até mesmo os métodos de ensino e os processos didáticos. E compreende, ainda, a prática de um "exercício estético" (FREIRE; SHOR, 2000, p. 144-146), embora quase sempre desprezada ou pouco valorizada.

Tal como a educação não pode ser neutra, também a educação dos educadores profissionais se afirma, inevitavelmente, como um projeto político-educativo em cujo seio a neutralidade axiológica não é possível, a não ser quando pretensamente apresentada como tal, caso em que se transforma num projeto puramente ideológico ao pretender esconder as suas opções e ao naturalizá-las, como se a formação de professores pudesse ser um projeto estritamente técnico-racional e, mesmo assim, sem opções e alternativas nesse plano, totalmente dominado pela racionalidade instrumental e por uma competência técnica unívoca. Em termos mais gerais, em diálogo com Antonio Faundez, Freire observou que "[...] ao ser tão enfatizada a apoliticidade da ciência e da educação, a sua politicidade termina por ser sublinhada. A negação da politicidade é finalmente percebida como um ato político..." (FREIRE; FAUNDEZ, 1998, p. 42).

Só num cenário de formação puramente técnica e pretensamente neutra, a erosão dos valores políticos, democráticos e morais dispensaria a formação de professores da sua responsabilidade ética. Esta, quando muito, seria limitada 
ao cumprimento mais ou menos mecânico das injunções administrativas, das regras heterónomas, das especificações técnicas da profissão docente ou, ainda, à reprodução mimética das "melhores práticas", de acordo com a conhecida pretensão de universalidade, descontextualizada, e de superior racionalidade de certas práticas locais baseadas em interesses específicos e dotadas de vocação hegemónica.

Pelo contrário, Freire fala de ética e de democracia substantiva porque, não sendo neutra, a educação demanda práticas educativas que resultam das decisões dos educadores, das suas opções a favor e contra, das suas presenças, omissões e demissões.

É precisamente por tudo isso que se torna imperativa a "eticidade do educador" (FREIRE, 1997a, p. 39) e que Edgar Morin (2002) considerou a ética um saber incontornável na educação do futuro. Mas não, por certo, mais um saber a ser simplesmente dito, ou mais uma disciplina curricular servida por novos métodos didáticos e por novas tecnologias educativas que dispensem a transmissão testemunhal.

Como observa Joan-Carles Mèlich (2010, p. 281), a "pedagogia do testemunho" funda-se na complementaridade entre o dizer e o mostrar, entre o professor e o mestre.

\section{A formação técnico-profissional dos professores e os riscos da sua didatização}

Em contraste com as concepções de formação de professores antes referidas, as quais, na sua pluralidade, não deixam de assumir a condição de educação cultural e ético-política de educadores, futuros (através da chamada formação inicial) e presentes (através da formação continuada), tem-se assistido, nas últimas décadas, a políticas de formação de professores de feição tecnicista e didatista. Isso resulta de várias e complexas razões, entre as quais merecem destaque: as políticas orientadas para a produção de resultados escolares em ambiente performativo e competitivo entre escolas, sistemas de ensino, países, etc.; as avaliações em larga escala, nacionais e internacionais, com recurso intensificado a exames e outras formas de avaliação estandardizada; o estreitamento do currículo, seja concedendo centralidade aos chamados "saberes essenciais" ou "disciplinas estruturantes", seja expurgando do currículo prescrito outras áreas e saberes agora considerados supérfluos e, por essa via, hierarquizando e "racionalizando" o currículo, diminuindo as cargas horárias letivas, despedindo 
professores que passaram a ser considerados excedentários; a maior abertura aos quesitos apresentados pelas empresas em termos de formação profissional, de acordo com exigências "vocacionais", de empregabilidade e de qualificação da força de trabalho, tendo em vista a modernização e a competitividade económicas; as pressões gerencialistas sobre os professores, exercidas por novos estilos de lideranças escolares, pelo escrutínio realizado através de plataformas eletrónicas, pela introdução de modos de gestão privada na escola pública; as tendências para a intensificação e a individualização do trabalho docente, especialmente dos professores mais jovens e dos precários, acompanhadas de uma perda de capacidade de ação coletiva, designadamente através da crise e da desvalorização política e social dos sindicatos e do associativismo docente; a crítica ideológica ao pensamento educacional e a tentativa de descredibilização das teorias pedagógicas e da pesquisa em educação, especialmente daquelas que são consideradas particularmente nefastas (como a sociologia da educação e a política educacional), ou dispensáveis (como, por exemplo, a história e a filosofia da educação), todas ocupando menos tempo e espaço na formação inicial (ou tendo simplesmente desaparecido), no entanto sempre invocadas por prejudicarem a formação científica na disciplina que o futuro professor virá a lecionar; o retorno a modelos de formação inicial de tipo bi-etápico, na Europa uma decorrência do Processo de Bolonha, que contribuíram para reforçar o já tradicional dualismo entre "formação científica" e "formação pedagógica" e para a sua organização sequencial, não integrada e, ademais, fortemente regulada pelo Estado em termos de componentes de formação e respectivas percentagens, atribuindo estatuto marginal à formação geral, não estritamente didática, em educação.

Em Portugal, como noutros países, a par de uma crescente perda de prestígio social da profissão docente, acompanhada por fenómenos de precariedade, de mobilidade e de desemprego, tem-se verificado uma crescente estratificação social e escolar por parte dos candidatos ao magistério. Mesmo considerando que a formação mínima de ingresso na profissão é o grau de mestrado (com natureza profissionalizante), isso não tem impedido um abaixamento do status destes cursos e, em diversas instituições, a emergência de uma lógica de formação de tipo técnico-profissional. Uma orientação marcada pela educação e formação "vocacional", como é chamada na Europa, e pelo regresso de várias dimensões que, no passado, tinham sido introduzidas pelas pedagogias científicas e racionalizadoras - das antigas taxonomias dos objetivos educacionais aos atuais padrões e resultados de aprendizagem -, favorecem o carácter instrumental da formação de professores, a sua fixação mais ou menos restrita em certos métodos e técnicas didáticos, em particulares dispositivos de avaliação pedagógica e em determinados processos de gestão da sala de aula. São sobretudo os recursos e os instrumentos que são considerados mais funcionais e eficazes, passíveis 
de prestação de contas, de mensuração e de produção de evidências, ou justificados por processos de benchmarking e de produção de resultados escolares considerados vantajosos em termos competitivos, aqueles que predominam.

A racionalidade técnico-instrumental adquiriu renovado protagonismo na formação de professores. Nada, de resto, que não tivesse já ocorrido, e por múltiplas vezes, no passado. O antes mencionado Coménio (1976, p. 73), em meados do século XVII, propunha uma didática magna, ou "arte de ensinar", baseada na possibilidade de "conduzir o método a uma certeza infalível", dessa feita conseguindo obter sempre o efeito esperado. Mas restringir a educação e a prática pedagógica a questões de metódica e à construção e adoção de novas tecnologias educativas e técnicas de ensino-aprendizagem, em busca de uma eficiência e de uma eficácia que se autolegitimam em termos formais, acarreta profundas consequências na formação docente. Desde logo porque, como afirma Manuel Reis (2003, p. 40), “A Didáctica está ao serviço de um Projeto Educativo, e não a educação ao serviço de um projeto didáctico". A reificação dos métodos pedagógicos e um certo fetichismo em torno das tecnologias e dos materiais didáticos representam, em certos contextos, riscos frequentes. Tal não é, contudo, inerente a todas e quaisquer concepções e práticas didáticas e metodológicas de educação e ensino, que são, aliás, indispensáveis na formação de professores. Podem, inversamente, constituir contextos privilegiados para o estabelecimento, intencional, de articulações com a politicidade da educação, que não deixa igualmente de as marcar de forma indelével, bem como com saberes filosóficos, psicológicos, sociológicos, entre outros, à revelia dos quais se torna mesmo difícil imaginar a substância das suas contribuições, pelo menos fora de um quadro restrito e atomizado dos fenómenos educativos e fora das relações íntimas com os conteúdos disciplinares a serem ensinados nas escolas. A didatização da formação de professores, portanto, é tão criticável como qualquer outro protagonismo insular, e exagerado, como seria a sua sociologização, ou psicologização, de pronto transformadas em pedagogismos e didatismos de signos variados, tanto mais quanto baseados em argumentos cientificistas ou em critérios apresentados como exclusivamente técnicos.

Como recordou Freire, em diálogo com Ira Shor, a possibilidade de transformar a educação transcende a mudança de métodos e de técnicas, o que não retira importância a estes, apenas relativiza o seu contributo, uma vez que o que se exige "[...] é o estabelecimento de uma relação diferente com o conhecimento e com a sociedade". (FREIRE; SHOR, 2000, p. 48). É em idêntica linha argumentativa que Moacir Gadotti (2006) critica a formação individualizada, e talvez também individualista, e competitiva do professor quando, segundo ele, "Mais do que uma formação técnica, a função do professor necessita de uma formação política para exercer com competência a sua profissão". (GADOTTI, 2006, p. 199). 
Exatamente no livro intitulado Política e educação, Freire (1997a, p. 53) reconhece a importância de "ensinar competentemente os conteúdos", tal como de "desvelar o mundo da opressão". Em contextos de formação de professores a questão ganha ainda maior relevância, simultaneamente educativo-cultural e ético-política, quando ambas as tarefas não são consideradas mutuamente exclusivas: quando a "competência científica" é considerada indispensável, tanto quanto é considerada incontornável a "claridade política". (FREIRE, 1997a, p. 53). É o que tem vindo a faltar na formação dos educadores profissionais, quando não são, para todos os efeitos relevantes, considerados trabalhadores culturais e sociais. Falta um projeto sólido e cientificamente ambicioso e exigente, capaz de assegurar a qualidade científica e pedagógica em todas as áreas de formação académica e profissional, contrariando as tradicionais cisões, distinções e diferenças de prestígio entre a preparação em torno dos conteúdos ou matérias a ensinar, a formação educacional geral e a formação metodológico-didática, como se no efetivo exercício das funções docentes tais contribuições pudessem ser isoladas umas das outras. Como se fosse possível um ensino-aprendizagem de conteúdos, organizado e permanente, sem ser por referência a uma teoria, explícita ou implícita, de educação; totalmente à margem de qualquer forma de organização do tempo e do espaço, de forma absolutamente ametódica e assistemática, fora de um contexto sociocultural, político e económico, acima de opções axiológicas, para além de objetivos, interesses, motivações, relações de poder. Em suma, e no limite, como se ocorresse já fora da sociedade humana, situação em que uma reflexão sobre o humano e a sua condição, sobre o devir e a esperança, sobre as desigualdades e a democracia, sobre a justiça, seria então dispensável ou supérflua.

\section{Nota final}

Nem mesmo numa situação dominada por uma visão tecnicista de educação, apresentada como axiologicamente neutra, centrada no treino de competências restritas, ou chegando ao ponto de confundir educação com doutrinação, ou amestramento, se chegaria ao ponto acima descrito, simplesmente porque só nas sociedades humanos há educação e porque no caso da educação escolar, organizada, esta é necessariamente resultante de uma política cultural e social. O que é possível, ao desvincular a educação, tal como a formação dos professores, de uma educação cultural e ético-política responsável, comprometida com a emancipação, a democracia e a cidadania ativa, com os direitos humanos e o combate a todas as formas de opressão e discriminação, é mais facilmente 
voltarmos a tombar perante o autoritarismo, a barbárie e a destruição que foram objeto das reflexões duras, e não condescendentes, de Theodor Adorno (2000), especialmente a propósito da educação após Auschwitz.

A emancipação e a autonomia, contra uma educação domesticada e altamente administrada, são especialmente exigentes. No último livro que publicou, intitulado Pedagogia da autonomia, Freire (1996) apresentou um vasto conjunto de exigências e de saberes que considerou necessários à prática educativa, desde a "rigorosidade metódica" e da "pesquisa", ao "diálogo" e ao "querer bem aos educandos". Mas todas as exigências ali apontadas tinham sido emblematicamente sintetizadas quando Freire (2000, p. 29), no livro $A$ sombra desta mangueira, e em apenas duas linhas, escreveu: "Na verdade, a educação precisa tanto da formação técnica, científica e profissional quanto do sonho e da utopia".

Embora inseparáveis da história humana, os dois últimos quesitos têm-se revelado raros, e não apenas na educação, mas mais generalizadamente em tempos de crise e de distopia.

\section{REFERÊNCIAS}

ADORNO, T. W. Educação e emancipação. Rio de Janeiro: Paz e Terra, 2000.

COBEN, D. Gramsci y Freire, héroes radicales. Políticas de educación de adultos. Buenos Aires: Fundación Paidiea/Miño y Dávila, 2001.

COMÉNIO, J. A. Didática magna. Tratado da arte universal de ensinar tudo todos. Lisboa: Fundação Calouste Gulbenkian, 1976.

DEWEY, J. Democracia e educação. Lisboa: Didáctica Editora, 2007.

FREIRE, P. Pedagogia do Oprimido. Porto: Afrontamento, 1975.

FREIRE, P. Pedagogia da Autonomia. Saberes necessários à prática educativa. Rio de Janeiro: Paz e Terra, 1996.

FREIRE, P. Política e Educação. São Paulo: Cortez, 1997a.

FREIRE, P. Professora sim, tia não. Cartas a quem ousa ensinar. São Paulo: Olho d'Água, $1997 b$.

FREIRE, P. Pedagogia da Esperança. Um reencontro com a Pedagogia do Oprimido. Rio de Janeiro: Paz e Terra, 1997c.

FREIRE, P. À sombra desta mangueira. São Paulo: Olho d'Água, 2000. 
FREIRE, P. Ação cultural para a liberdade e outros escritos. Rio de Janeiro: Paz e Terra, 2001.

FREIRE, P.; FAUNDEZ, A. Por uma pedagogia da pergunta. Rio de Janeiro: Paz e Terra, 1998.

FREIRE, P.; SHOR, I. Medo e ousadia. O cotidiano do professor. Rio de Janeiro: Paz e Terra, 2000.

GADOTTI, M. Paulo Freire e a boniteza do sonho de ensinar-e-aprender com sentido. In: SCOCUGLIA, A. C. (Org.). Paulo Freire na história da educação do tempo presente. Porto: Afrontamento, 2006. p. 191-217.

GRAMSCI, A. Selections from the prison notebooks. Londres: Lawrence and Wishart, 1971.

HELVETIUS, C.-A. De l'homme, de ses facultés intellectuelles et de son éducation Londres: Chez la Société Typographique, 1773. v. I.

LIMA, L. C. A educação faz tudo? Crítica ao pedagogismo na sociedade da aprendizagem. Revista Lusófona de Educação, Lisboa, v. 15, p. 41-54, 2010.

LIMA, L. C. Crítica da educação indecisa: a propósito da Pedagogia da Autonomia de Paulo Freire. Revista e-curriculum, São Paulo, v. 7, n. 3, p. 1-12, 2011.

MARX, K. Teses sobre Fuerbach. In: MARX, K.; ENGELS, F. Antologia filosófica. Lisboa: Estampa, 1971. p. 21-15.

MARX, K.; ENGELS, F. A sagrada família. São Paulo: Boitempo, 2011.

MAYO, P. Gramsci, Freire \& adult education. Possibilities for transformative action. Londres: Zed Books, 1999.

MÈLICH, J.-C. Ética de la compassión. Barcelona: Herder, 2010.

MIALARET, G. La formation des enseignants. Paris: Presses Universitaires de France, 1977.

MORIN, E. Os sete saberes para a educação. Lisboa: Instituto Piaget, 2002.

NÓVOA, A. Le temps des professeurs. Analyse socio-historique de la profession enseignante au Portugal (XVIIIe-XXe siècle). Lisboa: Instituto Nacional de Investigação Científica, 1987.

REIS, M. Ética profissional para professores e educadores. Guimarães: Livraria Ideal Editora/Centro de Estudos do Humanismo Crítico, 2003.

TARDIF, M.; LESSARD, C. O trabalho docente. Elementos para uma teoria da docência como profissão de interações humanas. Petrópolis: Vozes, 2007. 